\title{
Thrombosis in Iron Deficiency and Iron Deficiency Anemia: A Review of our Cases and the Relevant Literature
}

\author{
${\text { Ceren Kılc1 }{ }^{1} \text {, Lale Olcay }}^{1 *}$, Taner Sezer ${ }^{1}$, I Zafer Ecevit ${ }^{1}$, Murat Özkan ${ }^{2}$ and Birgül Varan ${ }^{1}$ \\ ${ }^{1}$ Department of Pediatrics, Baskent University Faculty of Medicine, Ankara \\ ${ }^{2}$ Department of Cardiovascular Surgery, Baskent University Faculty of Medicine, Ankara
}

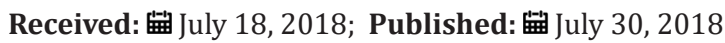

*Corresponding author: Lale Olcay, Baskent University Faculty of Medicine, Department of Pediatrics, Unit of Pediatric HematologyOncology, Mareşal Fevzi Çakmak Caddesi, Şehit Temel Kuğuluoğlu Sokak, No:24, 06490, Bahçelievler, Ankara, Turkey

\begin{abstract}
We evaluated our thrombosis cases for iron deficiency (ID) or iron deficiency anemia (IDA) retrospectively and reviewed the literature. We established that iron parameters were studied in 17 of 64 patients with thrombosis and 2 of 17 patients had IDA. Case 1 (age 16, female) had occlusions in sigmoid and transverse sinuses and right jugular vein and case 2 (age 15, male) had infarct in right cerebellar hemisphere. While case 1 additionally had mastoiditis, high Factor (F) VIII and PAI 4G/5G polymorphism, case 2 who underwent a recent aortic graft insertion operation for aortic aneurysm had high serum lipids, lipoprotein a, homocysteine, FVIII, d-dimer. Of 54 thrombosis cases with ID/IDA in the literature, cerebral thrombosis made up of $70.4 \%$ of all the cases, venous cerebral occlusions comprising $100 \%$ and $66 \%$ of venous thrombosis in children and adults respectively. Our findings show that ID/ IDA may be a risk factor for thrombosis, especially in cerebral veins.
\end{abstract}

Keywords: Iron deficiency anemia; Coagulation; Thrombosis; Thromboembolism

\section{Introduction}

Many cases of thrombosis have been reported in both children and adults, associated with iron deficiency (ID) or ID anemia (IDA) so far [1-40]. Additionally, the frequency of severe anemia [1] or IDA [2] in adults with cerebral [1] or deep venous thrombosis with/without pulmonary embolism [2] were shown significantly higher than that of the healthy controls. We previously showed by thromboelastogram that children with IDA had a tendency to thrombosis [41]. Herein, we evaluated our patients with IDA and thromboembolism followed in our clinic and reviewed the relevant literature (Tables 1-3).

\section{Materials and Methods}

We examined the charts of our patients treated for thrombosis during 2013-2016 and had concomitant IDA/ID; additionally we studied the literature between 1972-2016, through 'EntrezPubMed and Turkish Citation Index' databases, matching the key words 'thrombosis, thromboembolism, hypercoagulability; abnormal coagulation' with 'ID or IDA'

\section{Results}

Our search revealed that only 17 out of 64 patients with thrombosis diagnosed in our clinic during this period had been evaluated for iron parameters and only the 2 had IDA. These cases are presented below.

\section{Case 1 (O.E.)}

A 16-year-old girl was admitted due to headache, nausea, vomiting. She was diagnosed as otitis media (right) two weeks before and received antibiotics for seven days. A few days later, a continuous, blunt headache near right ear and right hemicranium propagating towards the right orbita developed which was accompanied by blurred vision, nausea and vomiting. Her physical examination revealed pallor, nasal discharge, bilateral papilledema and a systolic murmur of grade II/VI on the tract of right jugular vein. Cerebral magnetic resonance (MR) imaging (MRI) was compatible with mastoiditis and right jugular vein thrombosis. Cerebral MR venography revealed obliteration of the transverse 
sinus and the right jugular vein at the sigmoid sinus level. She had increased Factor (F) VIII and plasminogen activator inhibitor (PAI) 4G/5G polymorphism and IDA. The other laboratory findings are presented in Table 1. She received antibiotics for six weeks, low molecular weight heparin (LMWH) for six months and oral iron for three months. The cerebral MRI, cerebral MR venography taken at the end of the 2 nd month revealed normal. She had been well for 24 months of follow-up.

\section{Case 2 (EA)}

A 15 3/12-year-old boy was admitted to our clinic due to slight amnesia which developed 5 days after aortic graft insertion operation done for ascending aortic aneurysm. He was operated for aortic coarctation at 7 months of age. His physical examination revealed grade II/VI systolic murmur at the right 2 nd intercostal space and little confusion in recalling the near past. The cerebral MRI and diffusion MRI revealed acute infarct in the right cerebellar hemisphere. The electroencephalogram (EEG) was normal. He had IDA, vitamin B12 (VB12) and folic acid deficiencies, elevation levels of homocysteine, FVIII, lipoprotein a, very light density lipoproteins, triglycerides, d-dimer, C-reactive protein (Table 1). He was started prednisolone, lansoprazole, acetylsalicylic acid, LMWH. Amnesia disappeared three days later. Iron and VB12 therapies were added after his condition stabilized. Anti thrombotic therapy was continued with LMWH for six months. He has been well for the 18 months of follow-up.

Table 1: Some characteristics of cases with thrombosis and iron deficiency anemia in our clinic.

\begin{tabular}{|c|c|c|c|c|c|c|c|}
\hline \multirow[b]{2}{*}{ Patient } & \multirow[b]{2}{*}{ Thrombosis } & Age & \multirow{2}{*}{$\begin{array}{c}\text { Hb / MCV / SI / } \\
\text { TIBC / TS / fer } \\
\text { / thrombocyte } \\
\text { count }\end{array}$} & \multirow[b]{2}{*}{$\begin{array}{l}\text { Treatment / } \\
\text { Last status }\end{array}$} & \multirow[b]{2}{*}{ Radiologic Tests } & \multirow[b]{2}{*}{$\begin{array}{c}\text { Additional } \\
\text { Tested Factors }\end{array}$} & \multirow{2}{*}{$\begin{array}{c}\text { Accompanying } \\
\text { Systemic } \\
\text { Disease/ } \\
\text { Condition } \\
\end{array}$} \\
\hline & & $\begin{array}{l}\text { (y, mo) / } \\
\text { Gender }\end{array}$ & & & & & \\
\hline O.E. & $\begin{array}{l}\text { Right jugular } \\
\text { vein, sigmoid } \\
\text { and transverse } \\
\text { sinus }\end{array}$ & $17 y, W$ & $\begin{array}{c}\text { Hb: } 7.65 \text { / MCV: } \\
\text { 59.1 / SI: } 20 \\
\text { / TIBC: } 409 \\
\text { / TS: } 3 \text { / fer: } \\
\text { 2.6 / thromb: } \\
\text { 320000* }\end{array}$ & $\begin{array}{l}\text { LMWH, iron / } \\
\text { Full recovery }\end{array}$ & $\begin{array}{l}\text { Cerebral MRI: } \\
\text { Inflammatory } \\
\text { signals in the } \\
\text { right mastoid } \\
\text { cellules and signs } \\
\text { of thrombus in the } \\
\text { right jugular vein. } \\
\text { Cerebral MR } \\
\text { venography: Total } \\
\text { obliteration of } \\
\text { flow in the right } \\
\text { jugular vein at the } \\
\text { sigmoid sinus level } \\
\text { and nearly total } \\
\text { obliteration in the } \\
\text { transverse sinus. } \\
\text { Diffusion MRI: No } \\
\text { acute infarct. } \\
\text { Cerebral } \\
\text { angiography: } \mathrm{N} \\
\text { Orbital MRI: } \mathrm{N} \text {, } \\
\text { Inner ear CT: } \mathrm{N} \\
\text { Carotid Doppler: } \mathrm{N} \\
\text { Chest X-ray: } \mathrm{N} \\
\text { Echocardiography: } \\
\mathrm{N} \text {. } \\
\text { Temporal CT: } \\
\text { Aeration of middle } \\
\text { ear and mastoid } \\
\text { bone } \\
\text { Odiometry: } \mathrm{N} \\
\text { Impedance tests: } \mathrm{N}\end{array}$ & $\begin{array}{l} \\
\\
\text { PT, aPTT, TT, } \\
\text { Pro C, Pro S, } \\
\text { vWF, ATIII, } \\
\text { FI, FV, VB12, } \\
\text { homocysteine, } \\
\text { d-dimer, FDP, } \\
\text { FA, cholesterol, } \\
\text { LDL, HDL, VLDL, } \\
\text { lipoprotein a, } \\
\text { C3, C4: N, ACA, } \\
\text { APA, LA, ANA, } \\
\text { anti DNA, PNH } \\
\text { clone, Factor } \\
\text { V Leiden, Prt } \\
\text { G20210A, } \\
\text { MHTFR C677T } \\
\text { and A1298C } \\
\text { mutations: (-) } \\
\text { FVIII: \%221 } \\
\text { (High), CRP: } \\
\text { 8.5mg/dl (High) } \\
\text { PAI 4G/5G } \\
\end{array}$ & $\begin{array}{l}\text { Concomitant } \\
\text { mastoiditis }\end{array}$ \\
\hline E.A. & $\begin{array}{l}\text { Right cerebellar } \\
\text { hemisphere } \\
\text { infarct (cranial } \\
\text { MRI and } \\
\text { diffusion MRI) }\end{array}$ & $15 y, M$ & $\begin{array}{c}\text { Hb: } 9.1 \text { / MCV: } \\
\text { 85.7 / SI: } 45 \text { / } \\
\text { TIBC: } 336 \text { / } \\
\text { TS: } 11 \text { / fer: } 11.6 \\
\text { / thromb: } 63600\end{array}$ & $\begin{array}{l}\text { LMWH, iron, } \\
\text { VB12 / Low } \\
\text { fat diet, /Full } \\
\text { recovery }\end{array}$ & & $\begin{array}{c}\text { aPTT, TT, Pro } \\
\text { C, Pro S, vWF, } \\
\text { ATIII, FV, FDP, } \\
\text { cholesterol, LDL, } \\
\text { HDL, fibrinogen, } \\
\text { C3, C4: N } \\
\text { ACA, APA, LA, } \\
\text { Anti DNA, PNH } \\
\text { clone: (-), }\end{array}$ & $\begin{array}{c}\text { Aortic } \\
\text { coarctation, } \\
\text { Ascending aortic } \\
\text { aneurysm }\end{array}$ \\
\hline
\end{tabular}




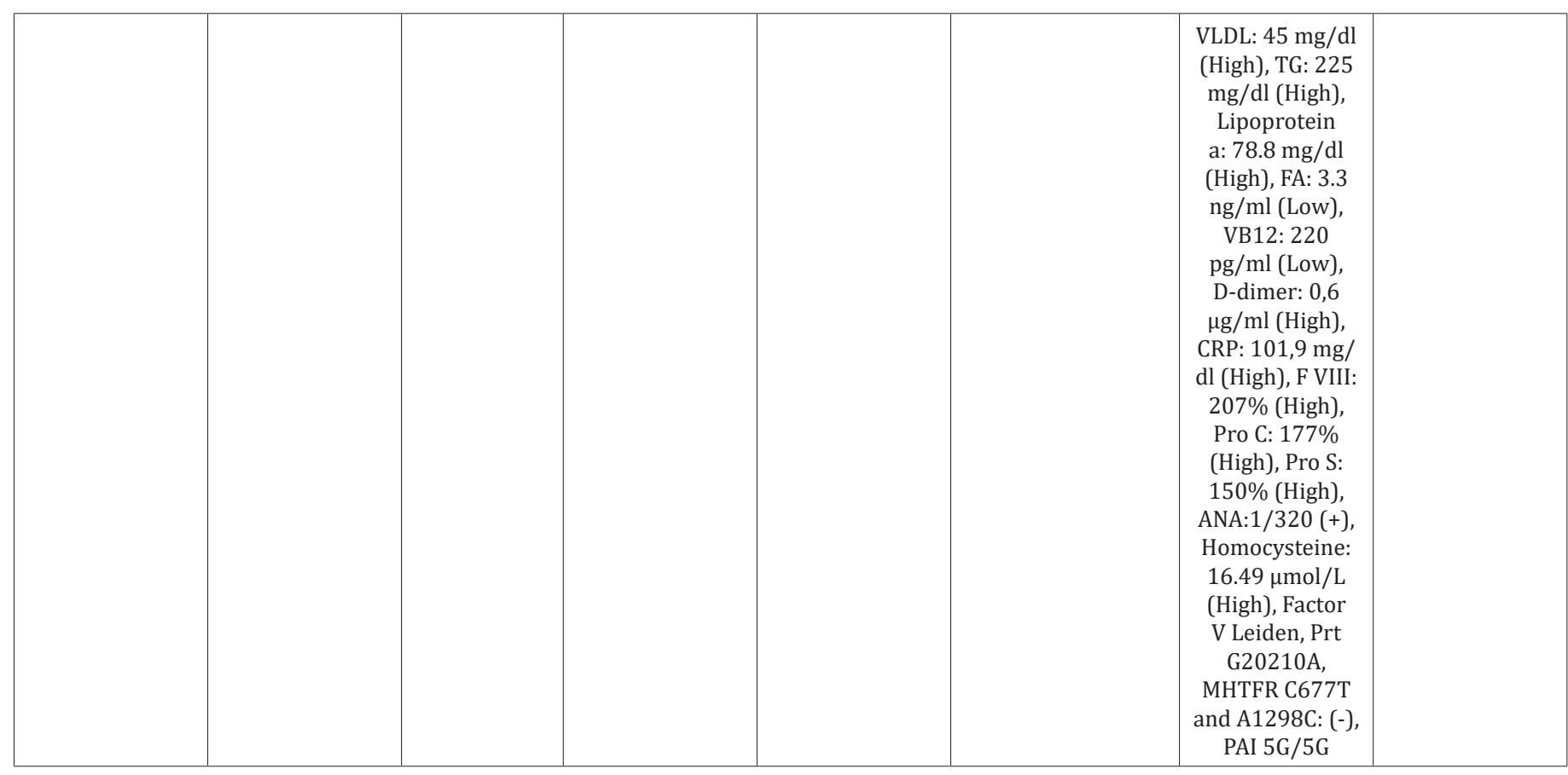

Abbreviations (Alphabetic order): ACA: Anti cardiolipin antibody; ANA: Antinuclear antibody; Anti -DNA: Anti deoxyribonucleic acid; APA: Antiphospholipid antibody; ATIII: Anti thrombin III; C3: Complement 3; C4: Complement 4; CRP: C-reactive protein; CT: Computerized tomography; F: Factor; FA: Folic acid; FDP: Fibrin degradation products; HDL: high density lipoprotein; H: High; LA: Lupus anticoagulant; LDL: low density lipoprotein; M: Male; MHTFR: Methylene tetrahydrofolate reductase enzyme; MRI: Magnetic resonance imaging; N: Normal; PAI-1: Plasminogen activator inhibitor-1; PNH: Paroxysmal nocturnal hemoglobinuria; Pro C: Protein C; Pro S: Protein S; Prt: Prothrombin; PT: Prothrombin time; aPTT: Activated thromboplastin time; TG: Triglyceride; TT: Thrombin time; VB12: Vitamin B12; VLDL: very low density lipoprotein; vWF: Von Willebrand factor; W: Woman

\section{Literature Review}

We established 54 cases with thrombosis and ID/IDA in the literature. The children and adults were almost equally affected ( $48.1 \%$ children, $51.8 \%$ adult), female/male ratio being 1.2 in children, 3.6 in adults. Veins were affected more than the arteries both in children and adults ( $73.1 \%$ and $53.6 \%$ respectively). Cerebral veins were occluded in $100 \%$ and $66.6 \%$ of the children and adults with thrombosis respectively. All the occluded non-cerebral veins in adults were retinal veins. The most common occluded arteries were the cerebral ones in children $(85.7 \%)$ and non-cerebral Table 2: Characteristics of the patients in the literature who developed thrombosis and have underlying iron deficiency anemia.

\begin{tabular}{|c|c|c|c|c|c|c|}
\hline Literature & Thrombosis & $\begin{array}{c}\text { Age (y, } \\
\text { mo) / } \\
\text { Gender }\end{array}$ & $\begin{array}{c}\text { Case } \\
\text { Hb/MCV/SI/TIBC/TS/ } \\
\text { fer/thrombocyte count/ } \\
\text { others }\end{array}$ & $\begin{array}{c}\text { Treatment/Last } \\
\text { status }\end{array}$ & $\begin{array}{c}\text { Additional Tested } \\
\text { Factors }\end{array}$ & $\begin{array}{c}\text { Accompanying } \\
\text { systemic disease/ } \\
\text { condition }\end{array}$ \\
\hline $\begin{array}{l}\text { BelmanAL } \\
\text { et al. [4] }\end{array}$ & $\begin{array}{l}\text { Straight sinus and } \\
\text { the vein of Galen } \\
\text { (hemorrhagic } \\
\text { infarct in basal } \\
\text { ganglia and } \\
\text { thalami) }\end{array}$ & $22 \mathrm{mo}, \mathrm{M}$ & $\begin{array}{l}\text { Hb: } 6 \text { / MCV: } 57 \text { / SI:NA } \\
\text { / TIBC: } 427 \text { / TS:NA/fer: } \\
\text { 5 / throm: } 540000 ; \text { bone } \\
\text { marrow: Iron stores absent }\end{array}$ & $\begin{array}{l}\text { Dexamethasone, } \\
\text { antibiotics, iron/ } \\
\text { resolution at 5th mo. }\end{array}$ & $\begin{array}{l}\text { RF, ANA: (-); Hb } \\
\text { electrophoresis, ATIII, pr } \\
\text { C, pr S, osmotic fragility, } \\
\text { G6PD, PT, aPTT, Factor } \\
\text { X, pyruvate kinase, bone } \\
\text { scan: N }\end{array}$ & Left otitis media \\
\hline
\end{tabular}

arteries in adults (76.9\%) mostly involving carotid artery (Tables 2 \&3). The rates of overall involvement of cerebral vessels in children and adults were $96.2 \%$ and $46.4 \%$ of all occlusions respectively (Tables 2 \& 3). Nine out of 50 (18\%) cases in the literature who were evaluated for other prothrombotic risk factors [3-15,17-40] had at least one risk factor like decreased protein S, Factor V Leiden, prothrombin G20210A mutations, increased Factor VIII, fibrinogen, lipoprotein a, cholesterol, anticardiolipin antibody, d-dimer, PAI, thrombin antithrombin complex levels and hemoglobin ( $\mathrm{Hb}) \mathrm{S}$ trait. Additionally four cases had patent foramen ovale. 


\begin{tabular}{|c|c|c|c|c|c|c|}
\hline \multirow[t]{2}{*}{$\begin{array}{l}\text { Balcı K et } \\
\text { al. [5] }\end{array}$} & $\begin{array}{l}\text { Internal cerebral } \\
\text { veins, vein of } \\
\text { Galen, extension } \\
\text { into inferior } \\
\text { sagittal \& left } \\
\text { transverse sinus } \\
\text { (Bilateral thalamic } \\
\text { \& basal ganglia } \\
\text { defect) }\end{array}$ & $38 \mathrm{y}, \mathrm{W}$ & $\begin{array}{c}\text { Hb: } 6.8 \text { / MCV: } 58 \text { / SI: } 22 \text { / } \\
\text { TIBC: NA/ TS: NA/ fer: } 9.9 \\
\text { / throm:560000 }\end{array}$ & $\begin{array}{l}\text { LMWH, } \\
\text { warfarin,eryth- } \\
\text { rocyte transfusions, } \\
\text { iron/Full recovery }\end{array}$ & $\begin{array}{l}\text { Pr C, Pr S, ATIII, PT, aPTT, } \\
\text { TT, Fibrinogen:N; } \\
\text { ANA, anti ds DNA, APA, } \\
\text { LA, ANCA: (-); } \\
\text { CSF protein:Mildly } \\
\text { high, tumor markers, } \\
\text { abdominal USG, } \\
\text { thoracic \& abdomen } \\
\text { CT, gynaecologic } \\
\text { examinations: N }\end{array}$ & NA \\
\hline & $\begin{array}{l}\text { The veins of Galen } \\
\text { \& Rosenthal, } \\
\text { extension into } \\
\text { straight \& left } \\
\text { transverse sinus } \\
\text { (Bilateral thalamic } \\
\text { \& basal ganglia } \\
\text { defect) }\end{array}$ & $18 \mathrm{y}, \mathrm{W}$ & $\begin{array}{l}\text { Hb: } 5.7 \text { / MCV: } 52.6 \text { / SI: } 42 \\
\text { / TIBC: NA / TS: NA / fer: } \\
\text { 8.8, thromb: } 640000\end{array}$ & $\begin{array}{l}\text { LMWH, warfarin,ery- } \\
\text { throcyte transfusions, } \\
\text { iron/Full recovery }\end{array}$ & $\begin{array}{l}\text { PT, aPTT, TT, fibrinogen, } \\
\text { ATIII, Pr C, Pr S, CSF } \\
\text { protein: N; APA, LA: } \\
\text { (-); abdominal USG, } \\
\text { endoscopy, rectoscopy, } \\
\text { gynaecological } \\
\text { examinations: N }\end{array}$ & NA \\
\hline \multirow[t]{6}{*}{$\begin{array}{c}\text { Hartfield DS } \\
\text { et al. [3] }\end{array}$} & $\begin{array}{c}\text { Straight sinus, } \\
\text { (Thalamic infarct) }\end{array}$ & $18 \mathrm{mo}, \mathrm{W}$ & $\begin{array}{l}\text { Hb: } 6.7 \text { / MCV: } 60 \text { / SI: NA / } \\
\text { TIBC: NA/ TS: NA/ fer: NA/ } \\
\text { throm: } 972000\end{array}$ & Iron/ Full recovery & $\begin{array}{c}\text { Screening tests including } \\
\text { ANA: }(-) \\
\text { (detail NA) }\end{array}$ & $\begin{array}{c}\text { Gastroenteritis, } \\
\text { history of recurrent } \\
\text { otitis media }\end{array}$ \\
\hline & $\begin{array}{l}\text { Superior sagittal } \\
\text { sinus }\end{array}$ & $12 \mathrm{mo}, \mathrm{W}$ & $\begin{array}{l}\text { Hb: } 7.7 \text { / MCV: } 55 \text { / SI: } 2 \text { / } \\
\text { TIBC: 43; TS:<5\% / fer: <5 } \\
\text { / throm: } 380000\end{array}$ & $\begin{array}{l}\text { Iron, dexamethasone, } \\
\text { heparin, warfarin / } \\
\text { Full recovery }\end{array}$ & $\begin{array}{c}\text { Lipid profiles: } \mathrm{N} \\
\text { Metabolic screen: (-) }\end{array}$ & Gastroenteritis \\
\hline & $\begin{array}{l}\text { Cerebral artery } \\
\text { Nonhemorrhagic } \\
\text { infarct (basal } \\
\text { ganglia/internal } \\
\text { capsule) }\end{array}$ & $11 \mathrm{mo}, \mathrm{W}$ & $\begin{array}{l}\text { Hb: } 12.6 \text { / MCV: } 78 \text { / SI: } 8 \\
\text { / TIBC: } 57 \text { / TS: } 14 \% \text { / fer: } \\
\text { NA / throm: } 693000\end{array}$ & $\begin{array}{l}\text { Iron, ASA/Full } \\
\text { recovery }\end{array}$ & $\begin{array}{l}\text { Metabolic screen: }(-), \\
\text { small PFO }\end{array}$ & $\begin{array}{l}\text { Recent upper } \\
\text { respiratory tract } \\
\text { infection }\end{array}$ \\
\hline & $\begin{array}{c}\text { Middle } \\
\text { Cerebral Artery } \\
\text { (Nonhemorrhagic } \\
\text { infarct) }\end{array}$ & $18 \mathrm{mo}, \mathrm{W}$ & $\begin{array}{l}\text { Hb: } 11.4 \text { / MCV: } 69 \text { / SI: NA } \\
\text { / TIBC: NA / TS: NA / fer: } \\
\text { NA / throm: } 373000\end{array}$ & $\begin{array}{c}\text { Iron/sequelae } \\
\text { (seizure disorder) }\end{array}$ & NA & $\begin{array}{c}\text { Recent } \\
\text { gastroenteritis }\end{array}$ \\
\hline & $\begin{array}{l}\text { Superior Sagittal } \\
\text { Sinus }\end{array}$ & $6 \mathrm{mo}, \mathrm{M}$ & $\begin{array}{c}\text { Hb: } 4.5 \text { / MCV: } 54 \text { / SI: } 1 \text { / } \\
\text { TIBC: } 61 \text { / TS: } \% 2 \text { / fer:<2 } \\
\text { / throm: } 657000\end{array}$ & $\begin{array}{l}\text { Iron, ASA /sequelae } \\
\text { (seizure disorder, } \\
\text { developmental delay) }\end{array}$ & Metabolic screen: (-) & $\begin{array}{l}\text { Gastroenteritis } \\
\text { (vomiting, fever) }\end{array}$ \\
\hline & $\begin{array}{c}\text { Middle } \\
\text { Cerebral artery } \\
\text { (Nonhemorrhagic } \\
\text { infarct) }\end{array}$ & $18 \mathrm{mo}, \mathrm{W}$ & $\begin{array}{l}\text { Hb: } 9.8 \text { / MCV: } 74 \text { / SI: } 9 \text { / } \\
\text { TIBC: } 68 \text { / TS: 13\% / fer: } \\
\text { NA / throm: } 531000\end{array}$ & $\begin{array}{l}\text { Iron, ASA/Full } \\
\text { recovery }\end{array}$ & Metabolic screen: (-) & $\begin{array}{c}\text { Varicella course } 3 \\
\text { weeks before }\end{array}$ \\
\hline
\end{tabular}




\begin{tabular}{|c|c|c|c|c|c|c|}
\hline \multirow[t]{2}{*}{$\begin{array}{c}\text { Kinoshita Y } \\
\text { et al. [6] }\end{array}$} & $\begin{array}{l}\text { Superior sagittal } \\
\text { sinus; extention } \\
\text { to transverse \& } \\
\text { sigmoid sinuses }\end{array}$ & $14 \mathrm{y}, \mathrm{M}$ & $\begin{array}{l}\text { Hb: } 7.4 \text { / MCV: } 56.8 \text { / SI: } 9 \\
\text { /TIBC: } 380 \text { / TS: } \% 2 \text { / fer: } \\
\text { NA /throm: } 289000\end{array}$ & $\begin{array}{l}\text { Hydration, LMW } \\
\text { dextran, warfarin, } \\
\text { iron /recanalization } \\
\text { but left sigmoid sinus } \\
\text { remained occluded, } \\
\text { vein of Labbe drained } \\
\text { into left transverse } \\
\text { sinus at 8th mo. }\end{array}$ & Pr C, ACA IgG, ATIII: N & Dehydration \\
\hline & $\begin{array}{l}\text { Superior sagittal } \\
\text { sinus } \\
\text { (hemorrhage in } \\
\text { right temporal } \\
\text { lobe, left parietal } \\
\text { lobe/ right frontal } \\
\text { lobe infarct) }\end{array}$ & $47 \mathrm{y}, \mathrm{M}$ & $\begin{array}{l}\text { Hb: } 15.7 \text { / MCV:78.1 / SI: } \\
\text { 44 / TIBC: NA/TS: NA / fer: } \\
\text { NA / throm: } 276000\end{array}$ & $\begin{array}{l}\text { Hydration, heparin, } \\
\text { warfarin, iron/ slight } \\
\text { left hemiparesis at } \\
\text { 2nd mo }\end{array}$ & Pr C, ACA IgG, ATIII: N & $\begin{array}{c}\text { Dehydration, } \\
\text { alcoholism }\end{array}$ \\
\hline $\begin{array}{l}\text { Sushil B et } \\
\text { al.[7] }\end{array}$ & $\begin{array}{l}\text { Internal cerebral } \\
\text { vein, vein of Galen, } \\
\text { straight sinus, } \\
\text { sigmoid sinus \& } \\
\text { Rosenthal basal } \\
\text { vein } \\
\text { (bilateral } \\
\text { hemorrhagic } \\
\text { infarct of } \\
\text { thalamus) } \\
\text { (on 7th day of oral } \\
\text { iron therapy) }\end{array}$ & $9 \mathrm{mo}, \mathrm{M}$ & $\begin{array}{c}\text { Hb: 4.1 / MCV: } 48 \text { / SI: } 7 \text { / } \\
\text { TIBC: NA / TS: NA / fer: NA } \\
\text { / throm: } 866000\end{array}$ & $\begin{array}{l}\text { LMWH, continuation } \\
\text { of iron / Partial } \\
\text { recanalization at } 3 \\
\text { mo. }\end{array}$ & $\begin{array}{c}\text { Echocardiography, } \\
\text { Hb electrophoresis, } \\
\text { biochemistry, CRP, urine } \\
\text { test: } \mathrm{N} \\
\text { Tests for prothrombotic } \\
\text { disorder: (-) (details NA) }\end{array}$ & NA \\
\hline Yokota H [8] & $\begin{array}{l}\text { Superior sagittal } \\
\text { sinus }\end{array}$ & $37 \mathrm{y}, \mathrm{W}$ & $\begin{array}{l}\text { Hb: } 7.7 \text { / MCV: } 70.1 \text { / SI:13 } \\
\text { / UIBC: } 286 \text { /TS:NA / fer: } \\
\text { 3.8/ throm: } 356000\end{array}$ & $\begin{array}{l}\text { Hydration, heparin, } \\
\text { warfarin, iron/full } \\
\text { recovery at 2nd mo. }\end{array}$ & $\begin{array}{c}\text { PT, CRP, thyroid } \\
\text { functions, pr C, pr S, } \\
\text { homocysteine, thoracic } \\
\text { \& abdominal CT, } \\
\text { abdominal USG, upper } \\
\text { GIS endoscopy: N; APA, } \\
\text { ANA, AMA, LA: (-); Factor } \\
\text { VIII: High; d-dimer, TAT: } \\
\text { Slightly high }\end{array}$ & No \\
\hline $\begin{array}{l}\text { Corrales- } \\
\text { Medina F et } \\
\text { al.[9] }\end{array}$ & $\begin{array}{l}\text { Vein of Galen, } \\
\text { sinus rectus, left } \\
\text { transverse sinus, } \\
\text { left internal } \\
\text { cerebral vein, } \\
\text { jugular Фbulb }\end{array}$ & $13 \mathrm{y}, \mathrm{W}$ & $\begin{array}{l}\text { Hb: } 5.1 \text { / MCV: } 63.6 \text { / SI: } \\
\text { NA / TIBC: NA / TS: NA / } \\
\text { fer: } 6 \text { / throm: } 483000\end{array}$ & $\begin{array}{l}\text { Heparin-warfarin } \\
\text { / Full recovery of } \\
\text { thrombosis but } \\
\text { gliosis in centrum } \\
\text { semiovale }\end{array}$ & $\begin{array}{l}\text { Pr C \& Pr S: Low } \\
\text { (normalized later), } \\
\text { other tests of } \\
\text { hypercoagulability: } \mathrm{N} \\
\text { (details NA) } \\
\text { Bleeding evaluation: } \mathrm{N}\end{array}$ & $\begin{array}{c}\text { Chronic } \\
\text { menorrhagia }\end{array}$ \\
\hline
\end{tabular}




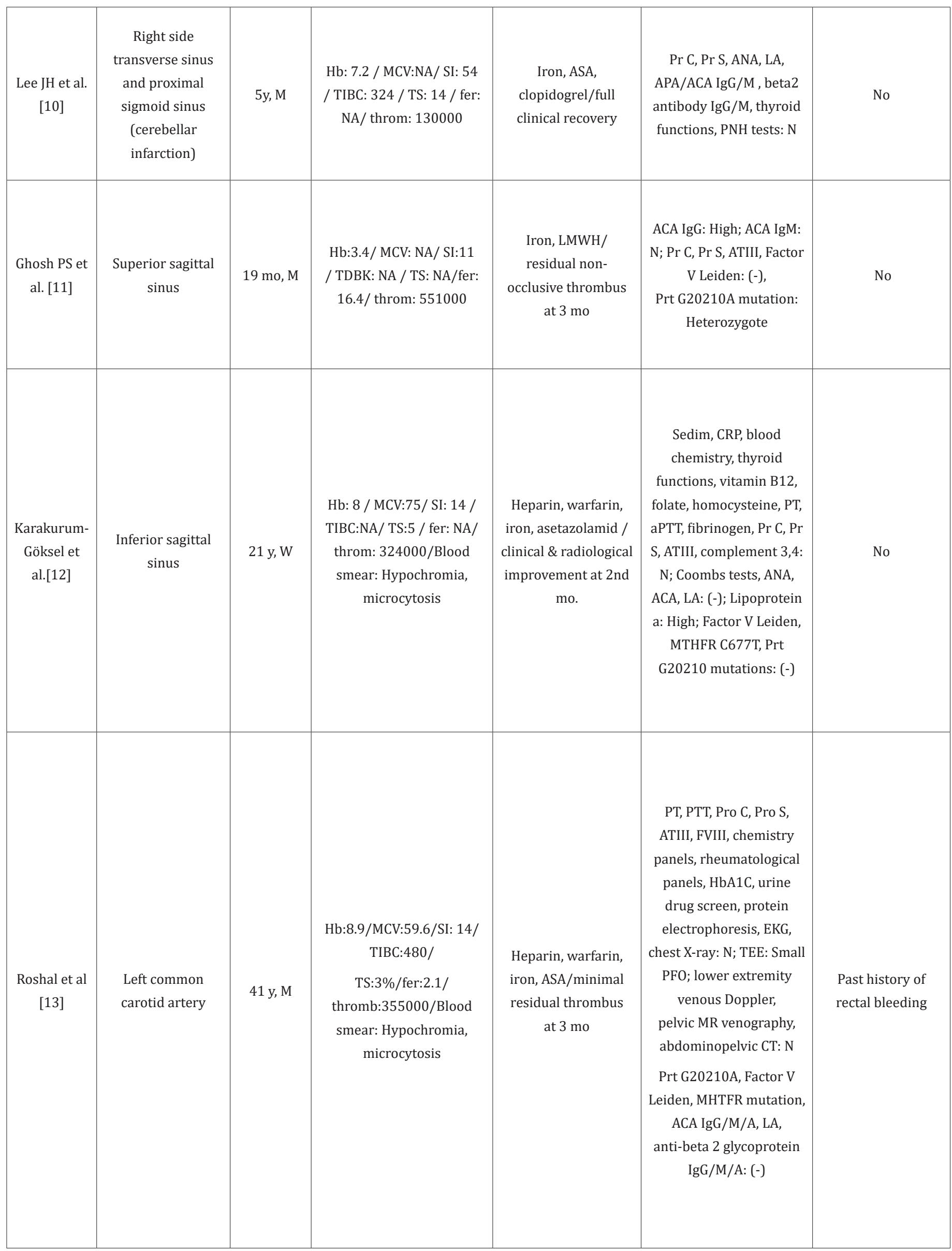




\begin{tabular}{|c|c|c|c|c|c|c|}
\hline $\begin{array}{c}\text { Saxena K et } \\
\text { al. [14] }\end{array}$ & $\begin{array}{l}\text { Bilateral atrial } \\
\text { thrombus/ right } \\
\text { middle cerebral } \\
\text { artery, then } \\
\text { right anterior } \\
\text { cerebral artery } \\
\text { (under heparin } \\
\text { therapy); Bilateral } \\
\text { pulmonary artery }\end{array}$ & $4 \mathrm{y}, \mathrm{W}$ & $\begin{array}{c}\text { Hb: } 5.8 \text { / MCV < } 50 \text { / SI: NA } \\
\text { / TIBC: NA / TS: NA / fer: } \\
\text { NA / throm: } 748000\end{array}$ & $\begin{array}{c}\text { Rehydration, } \\
\text { transfusion, } \\
\text { entubation, heparin, } \\
\text { fosphenytoin/ Brain } \\
\text { death, exitus }\end{array}$ & $\begin{array}{c}\text { Factor V Leiden } \\
\text { (heterozygous);Prt } \\
\text { G20210 A heterozygous; } \\
\text { MTHFR 677C / T } \\
\text { heterozygous; APA IgG: } \\
\text { High; } \\
\text { ATIII and homocysteine: } \\
\text { N }\end{array}$ & $\begin{array}{c}\text { Acute } \\
\text { gastrointestinal } \\
\text { hemorrhage, } \\
\text { compensated shock }\end{array}$ \\
\hline $\begin{array}{l}\text { Ogata T et } \\
\text { al. [15] }\end{array}$ & $\begin{array}{l}\text { Superior sagittal } \\
\text { sinus and cortical } \\
\text { veins }\end{array}$ & $55 \mathrm{y}, \mathrm{M}$ & $\begin{array}{l}\text { Hb: } 8.7 \text { / SI } 18 \text { / TIBC: } \\
\text { 522 / TS: } 3.4 \text { / fer: } 13.3 \text { / } \\
\text { throm: } 272000\end{array}$ & $\begin{array}{l}\text { Phenytoin, iron, } \\
\text { ulcer treatment / } \\
\text { Recanalization of } \\
\text { sagittal sinus at 4th } \\
\text { week }\end{array}$ & $\begin{array}{l}\text { D-dimer and TAT: High } \\
\text { PT,aPTT,fibrinogen, Pr C, } \\
\text { Pr S, ATIII, CRP, serum } \\
\text { protein constituents: N, } \\
\text { ANA, ANCA, proteinase3: } \\
\text { LA, ACA, anti- } \beta 2 \\
\text { glycoprotein I: (-);CSF: } \\
\text { N, Endoscopy: Stomach, } \\
\text { duedonum ulcers; } \\
\text { chest, abdominal CT, } \\
\text { scintigraphy: N }\end{array}$ & $\begin{array}{l}\text { Peptic ulcer } \\
\text { bleeding }\end{array}$ \\
\hline $\begin{array}{c}\text { Akins PT et } \\
\text { al. [17] }\end{array}$ & $\begin{array}{l}\text { Right internal } \\
\text { carotid artery (in } \\
\text { the bulb) }\end{array}$ & $44 \mathrm{y}, \mathrm{W}$ & $\begin{array}{c}\text { Hb: } 6.6 \text { / MCV:56.6/ SI: < } \\
10 \text { / TIBC: } 399 \text { / TS: <3\%/ } \\
\text { fer: }<10 \text { / Tr: } 666000\end{array}$ & $\begin{array}{l}\text { Blood transfusions, } \\
\text { oxygen, ASA, heparin, } \\
\text { iron / Full recovery }\end{array}$ & $\begin{array}{c}\text { Biochemistry, chest x-ray, } \\
\text { lower extremity Doppler, } \\
\text { PT, aPTT, Pr C, Pr S, ATIII, } \\
\text { TSH, Hb electrophoresis: } \\
\text { N; ANA, ACA, PNH: -, TEE: } \\
\text { PFO }\end{array}$ & Menorrhagia \\
\hline & $\begin{array}{l}\text { Right internal } \\
\text { carotid artery } \\
\text { (right parietal } \\
\text { infarct) }\end{array}$ & $20 \mathrm{y}, \mathrm{W}$ & $\begin{array}{c}\text { Hb: } 6.3 \text { / MCV: 54,5 / SI: < } \\
\text { 10 / TIBC: } 355 \text { /TS:3\%/ } \\
\text { fer: < } 10 \text { / throm:544000 }\end{array}$ & $\begin{array}{l}\text { Phenytoin, heparin, } \\
\text { ASA, iron, blood } \\
\text { transfusion /residual } \\
\text { left upper-extremity } \\
\text { clumsiness }\end{array}$ & $\begin{array}{l}\text { Hb electrophoresis, } \\
\text { sedim, PT, PTT, Pr C, Pr } \\
\text { S, ATIII, lower extremity } \\
\text { Doppler, ventilation/ } \\
\text { perfusion scanning: N; } \\
\text { ACA, ANA, LA, PNH, } \\
\text { syphilis serologies: (-); } \\
\text { TEE: PFO }\end{array}$ & Migraine \\
\hline & $\begin{array}{l}\text { Left common } \\
\text { carotid artery }\end{array}$ & $39 \mathrm{y}, \mathrm{W}$ & $\begin{array}{l}\text { Hb: } 7.1 \text { / MCV: } 62.9 \text { / SI: } \\
\text { 20, TIBC: } 404 \text { / TS:5\% / } \\
\text { fer: < } 10 \text { / throm: } 652000\end{array}$ & $\begin{array}{l}\text { Blood transfusion, } \\
\text { iron, warfarin, } \\
\text { insulin, leuprolide } \\
\text { acetate/Recovery }\end{array}$ & $\begin{array}{c}\text { Hb electrophoresis, } \\
\text { sedim, PT, aPTT, Pr C, Pr } \\
\text { S, ATIII, ACA, ANA, PNH, } \\
\text { syphilis serologies: (-); } \\
\text { glucose \& cholesterol: } \\
\text { High }\end{array}$ & $\begin{array}{l}\text { Menorrhagia } \\
\text { (leiyomyoma) }\end{array}$ \\
\hline
\end{tabular}




\begin{tabular}{|c|c|c|c|c|c|c|}
\hline $\begin{array}{l}\text { Imai E et } \\
\text { al.[18] }\end{array}$ & $\begin{array}{l}\text { Left branch retinal } \\
\text { artery }\end{array}$ & $32 \mathrm{y}, \mathrm{M}$ & $\begin{array}{l}\text { Hb: } 6.4 \text { /MCV:71,1/ SI:10 } \\
\text { / TIBC:539 /TS:1.8\%/ fer: } \\
\text { 5.2 / throm: } 252000\end{array}$ & $\begin{array}{c}\text { Stellate ganglion } \\
\text { block, hyperbaric } \\
\text { oxygen, iron/partial } \\
\text { improvement in } \\
\text { visual acuity at } 4 \text { th } \\
\text { mo }\end{array}$ & $\begin{array}{l}\text { RF, ANA: (-); sedim, blood } \\
\text { chemistry, aPTT, ATIII, } \\
\text { fibrinogen, hepaplastin } \\
\text { test, thrombo test: N; } \\
\text { d-dimer: slightly high; } \\
\text { echocardiography, chest } \\
\text { x-ray, neck USG, brain } \\
\text { and orbita CT:N }\end{array}$ & No \\
\hline $\begin{array}{l}\text { Kirkham TH } \\
\text { et al. [19] }\end{array}$ & $\begin{array}{l}\text { Left central retinal } \\
\text { vein }\end{array}$ & $44 \mathrm{y}, \mathrm{W}$ & $\begin{array}{l}\text { Hb: 6.2/ MCV: NA / SI: 30/ } \\
\text { TIBC: NA / TS: NA / fer: NA } \\
\text { / throm: } 280000 \\
\text { Blood smear: Marked } \\
\text { hypochromia, anisocytosis, } \\
\text { poikilocytosis; Bone } \\
\text { marrow: No stainable iron }\end{array}$ & $\begin{array}{l}\text { Blood transfusion, } \\
\text { iron/fundus } \\
\text { normalized, visual } \\
\text { acuity } 6 / 5\end{array}$ & $\begin{array}{c}\text { PT, kaolin cephalin } \\
\text { time, fibrinogen, blood } \\
\text { chemistry, urine analysis: } \\
\text { N; ANA: (-); } \\
\text { Radiology of oesophagus, } \\
\text { stomach, small \& large } \\
\text { intestine: N; bone } \\
\text { marrow biopsy: No } \\
\text { stainable iron }\end{array}$ & Retinal hemorrhage \\
\hline \multirow[t]{2}{*}{$\begin{array}{l}\text { Kacer B et } \\
\text { al. [20] }\end{array}$} & $\begin{array}{l}\text { Left central retinal } \\
\text { vein }\end{array}$ & $37 \mathrm{y}, \mathrm{W}$ & $\begin{array}{l}\text { Hb: } 9.4 \text { / MCV:74.2/ SI:15/ } \\
\text { TIBC: 528/ TS:NA / fer:3 } \\
\text { / throm: Normal (numeric } \\
\text { value NA) }\end{array}$ & $\begin{array}{l}\text { Heparin, tPA, } \\
\text { iron/ visual acuity } \\
\text { recovered }\end{array}$ & $\begin{array}{l}\text { PT, PTT, ATIII, Pr C, Pr } \\
\text { S, FI, FII, FVII, FVIII, } \\
\text { FXII, vWF Ag, RistCoF, } \\
\text { heparin Cofactor II, } \\
\text { homocysteine, tPA, } \\
\text { PAI, histidine-rich } \\
\text { glycoprotein, CRP, sedim, } \\
\text { viral serology: N; LA, } \\
\text { ACA: (-) }\end{array}$ & No \\
\hline & $\begin{array}{l}\text { Right central } \\
\text { retinal vein }\end{array}$ & $50 \mathrm{y}, \mathrm{W}$ & $\begin{array}{c}\text { Hb: } 7.3 \text { / MCV: 62/ SI: 10/ } \\
\text { TIBC: NA / TS: NA / fer: <5 } \\
\text { / throm: } 390000\end{array}$ & $\begin{array}{l}\text { Heparin, steroid/ } \\
\text { No response to } \\
\text { treatment }\end{array}$ & NA & Hypermenorrhea \\
\hline Nagai T [21] & Central retinal vein & $29 \mathrm{y}, \mathrm{W}$ & $\begin{array}{l}\text { Hb: } 4.5 \text { / MCV: } 55 \text { / SI: } 5 \text { / } \\
\text { TIBC: } 535 \text { / TS: NA / fer: } 4 \\
\text { / throm: } 1020000\end{array}$ & $\begin{array}{l}\text { Iron/gradual } \\
\text { improvement }\end{array}$ & $\begin{array}{l}\text { Bone marrow: Increased } \\
\text { megakaryocytes, normal } \\
\text { karyotype }\end{array}$ & Myoma uteri \\
\hline $\begin{array}{l}\text { Matsuoka Y } \\
\text { et al. [22] }\end{array}$ & $\begin{array}{l}\text { Left central retinal } \\
\text { artery }\end{array}$ & $13 \mathrm{y}, \mathrm{W}$ & $\begin{array}{l}\text { Hb: 5.5/ MCV: 60/ SI: 45/ } \\
\text { TIBC: 450/ TS: NA / fer: } \\
\text { 18/ throm: } 534000\end{array}$ & $\begin{array}{l}\text { Urokinase, iron/good } \\
\text { visual acuity }\end{array}$ & $\begin{array}{l}\text { BUN, electrolites, plasma } \\
\text { proteins, viscosity, } \\
\text { glucose, lipids, urinalysis, } \\
\text { chest X-ray, sedim, EKG, } \\
\text { brain CT, orbit CT, neck } \\
\text { USG, abdominal USG: N }\end{array}$ & No \\
\hline
\end{tabular}




\begin{tabular}{|c|c|c|c|c|c|c|}
\hline $\begin{array}{c}\text { Shibuya Y et } \\
\text { al. [23] }\end{array}$ & $\begin{array}{l}\text { Left central retinal } \\
\text { vein }\end{array}$ & $21 \mathrm{y}, \mathrm{W}$ & $\begin{array}{l}\text { Hb: } 6.5 \text { / MCV: 66.4/ SI: } \\
\text { 44/ TDBK:529/ TS: NA / } \\
\text { fer: NA / throm: NA }\end{array}$ & $\begin{array}{l}\text { Iron/visual acuity } \\
\text { improved }\end{array}$ & NA & Anorexia nervosa \\
\hline $\begin{array}{c}\text { Knizley H } \\
\text { \&Noyes WD } \\
{[24]}\end{array}$ & $\begin{array}{l}\text { Transient ischemic } \\
\text { attack } \\
\text { (bilateral } \\
\text { papilledema and } \\
\text { right hemiparesis) }\end{array}$ & $42 y, M$ & $\begin{array}{l}\text { Hb: 5.1 / MCV: NA / SI: 43/ } \\
\text { TDBK:548/ TS:8/ fer: NA / } \\
\text { throm: } 1015000 \\
\text { Blood smear: } \\
\text { Hypochromia, target cells }\end{array}$ & $\begin{array}{c}\text { Iron/paresis \& } \\
\text { papilledema resolved } \\
\text { within } 72 \text { hours \& } 2 \\
\text { mo respectively }\end{array}$ & $\begin{array}{l}\text { Sickle cell preparation, } \\
\text { stool hematest: (-); } \\
\text { Hb A, clotting time, } \\
\text { urinalysis, creatinin, } \\
\text { glucose, chest\&skull } \\
\text { X-rays, brain scan, EKG, } \\
\text { upper GIS series \& small } \\
\text { bowel, barium enema: } \\
\text { N; proctosigmoidoscopy: } \\
\text { internal hemorrhoids }\end{array}$ & $\begin{array}{c}\text { Bronchial asthma, } \\
\text { congenital clubbing } \\
\text { of fingers/toes }\end{array}$ \\
\hline $\begin{array}{l}\text { Alexander } \\
\text { MB [25] }\end{array}$ & $\begin{array}{l}\text { Cerebrovascular } \\
\text { accident (Right } \\
\text { hemiparesis, } \\
\text { aphasia, but cranial } \\
\text { CT: N) }\end{array}$ & $42 \mathrm{y}, \mathrm{W}$ & $\begin{array}{l}\text { Hb: NA/ MCV: 62/ SI:19/ } \\
\text { TIBC: } 595 \text { / TS: } 3 \text { / fer: } 8 \text { / } \\
\text { throm: } 1736000\end{array}$ & $\begin{array}{l}\text { Heparin,dextran, ASA, } \\
\text { iron/resolution }\end{array}$ & $\begin{array}{l}\mathrm{Hb} \text { S, Coombs' tests, } \\
\text { fibrinogen, fibrin split } \\
\text { products, ANA: (-); } \\
\text { bone marrow aspirate: } \\
\text { Increased cellularity } \\
\text { with increased } \\
\text { megakaryocytes }\end{array}$ & Menorrhagia \\
\hline $\begin{array}{l}\text { Heller DS et } \\
\text { al. [26] }\end{array}$ & $\begin{array}{c}\text { Left middle } \\
\text { cerebral artery (on } \\
\text { 4th postoperative } \\
\text { day } \\
\text { (massive infarct } \\
\text { of left cerebral } \\
\text { hemisphere) }\end{array}$ & $26 \mathrm{y}, \mathrm{W}$ & $\begin{array}{l}\text { Hb: } 9.8 \text { / MCV: 77.6/ } \\
\text { SI: NA / TIBC: NA / TS: } \\
\text { NA / fer: NA / throm: } \\
\text { 786000/ blood smear: } \\
\text { Hypochromic, microcytic } \\
\text { erythrocytes }\end{array}$ & $\begin{array}{l}\text { Iron, mannitol, } \\
\text { dexamethasone, } \\
\text { intubation/death on } \\
\text { postoperative 13th } \\
\text { day }\end{array}$ & $\begin{array}{l}\text { PT, PTT, fibrin split } \\
\text { products: N, fibrinogen: } \\
\text { probably high (515); } \\
\text { autopsy: No vegetations, } \\
\text { no septal defects; spleen: } \\
\text { myeloid metaplasia; } \\
\text { marrow: Increased } \\
\text { megakaryocytes, } \\
\text { erythroid and myeloid } \\
\text { precursors, no stainable } \\
\text { iron, minimally increased } \\
\text { reticulin }\end{array}$ & $\begin{array}{c}\text { Multiple } \\
\text { myomectomies, } \\
\text { ovarian } \\
\text { endometriosis; } \\
\text { incipient } \\
\text { myeloproliferative } \\
\text { disorder }\end{array}$ \\
\hline $\begin{array}{l}\text { Boon IS et } \\
\text { al. [27] }\end{array}$ & $\begin{array}{l}\text { Left transverse } \\
\text { sinus }\end{array}$ & $18 \mathrm{y}, \mathrm{M}$ & $\begin{array}{c}\text { Hb: 7.4/ MCV: NA / SI: NA } \\
\text { / TIBC: NA / TS: NA / fer: } \\
\text { NA / throm: NA } \\
\text { (studies confirming iron } \\
\text { deficiency) }\end{array}$ & $\begin{array}{l}\text { LMWH, iron/ } \\
\text { Headache improved } \\
\text { at discharge (follow- } \\
\text { up NA) }\end{array}$ & $\begin{array}{c}\text { APA \&ACA: (-) } \\
\text { Hb electrophoresis: } \\
\text { sickle cell trait; } \\
\text { retroviral \& autoimmune } \\
\text { screens: (-); ova, } \\
\text { parasites, cysts on stool: } \\
\text { (-) } \\
\text { Factor VII: Low }\end{array}$ & NA \\
\hline $\begin{array}{l}\text { Nishiola K } \\
\text { et al. [28] }\end{array}$ & $\begin{array}{l}\text { Superior sagittal } \\
\text { sinus, left } \\
\text { transverse sinus }\end{array}$ & $47 \mathrm{y}, \mathrm{W}$ & $\begin{array}{c}\text { Hb: 7.6/ MCV: NA / SI: NA } \\
\text { / TIBC: NA / TS: NA / fer: } \\
\text { NA / throm: NA }\end{array}$ & $\begin{array}{l}\text { Heparin, warfarin, } \\
\text { antiplatelet drugs, } \\
\text { iron/ clinical } \\
\text { improvement; } \\
\text { sustained } \\
\text { disturbance in } \\
\text { occluded veins; } \\
\text { collaterals at 2nd } \\
\text { year }\end{array}$ & $\begin{array}{c}\text { CSF: increased cell counts } \\
\text { and protein; d-dimer, CA- } \\
\text { 125: High }\end{array}$ & Pelvic adenomyosis \\
\hline
\end{tabular}




\begin{tabular}{|c|c|c|c|c|c|c|}
\hline $\begin{array}{c}\text { Raso S et } \\
\text { al.[29] }\end{array}$ & $\begin{array}{c}\text { Abdominal } \\
\text { aorta (multiple } \\
\text { infarctions of the } \\
\text { spleen and the left } \\
\text { kidney) }\end{array}$ & $42 \mathrm{y}, \mathrm{W}$ & $\begin{array}{c}\text { Hb: NA/ MCV:NA, / SI: NA / } \\
\text { TIBC: NA / TS:NA / fer: 4/ } \\
\text { throm: } 1133000 \\
\text { After } 2 \text { weeks: } \\
\text { Hb:8.2 / MCV:60.2 / SI: } \\
\text { NA / TIBC: NA / TS:NA / } \\
\text { fer:NA/ throm: } 932000\end{array}$ & $\begin{array}{c}\text { Heparin, ASA, iron/ } \\
\text { Complete recovery at } \\
\text { 3rd mo }\end{array}$ & $\begin{array}{l}\text { Inflammation markers, } \\
\text { protein electrophoresis, } \\
\text { coagulation profile, } \\
\text { oncological markers: N; } \\
\text { JAK-2,calreticulin, } \\
\text { MPL mutations } \\
\text { Factor V Leiden, } \\
\text { Prt mutation (-); } \\
\text { autoimmunity markers: } \\
(-)\end{array}$ & $\begin{array}{l}\text { Gastroesophageal } \\
\text { reflux disease; } \\
\text { diverticular, } \\
\text { hemorrhoidal } \\
\text { disease in colon }\end{array}$ \\
\hline $\begin{array}{c}\text { Nicastro } \\
\text { Net al. [30] }\end{array}$ & $\begin{array}{c}\text { Superior sagittal } \\
\text { sinus, left sigmoid } \\
\text { / transverse } \\
\text { sinus, cortical } \\
\text { vein thrombosis } \\
\text { \& bilateral } \\
\text { pulmonary } \\
\text { embolism } \\
\text { (massive left } \\
\text { frontotemporal } \\
\text { hemorrhagic } \\
\text { infarction }\end{array}$ & $63 \mathrm{y}, \mathrm{W}$ & $\begin{array}{c}\text { Hb:3,4 / MCV: NA / SI:1 / } \\
\text { TIBC: NA / TS: NA / fer:2 / } \\
\text { throm: NA }\end{array}$ & $\begin{array}{l}\text { Blood transfusion, } \\
\text { heparin, } \\
\text { acenocoumarol/ } \\
\text { almost complete } \\
\text { recovery at } 1 \text { st mo }\end{array}$ & $\begin{array}{l}\text { Lower extremity Doppler, } \\
\text { VB12, folate, protein } \\
\text { electrophoresis: N; } \\
\text { Factor V Leiden, } \\
\text { Prt mutation, activated } \\
\text { Pr C resistance, APA: } \\
\text { (-); GIS endoscopies, } \\
\text { mammography, } \\
\text { endovaginal } \\
\text { echocardiography, } \\
\text { thorax+abdomen+pelvic } \\
\text { CT: N }\end{array}$ & Vegetarianism \\
\hline $\begin{array}{c}\text { Habis A et } \\
\text { al. [31] }\end{array}$ & $\begin{array}{l}\text { Superior sagittal } \\
\text { sinus thrombosis, } \\
\text { extension into } \\
\text { proximal left } \\
\text { transverse sinus }\end{array}$ & $18 \mathrm{mo}, \mathrm{M}$ & $\begin{array}{l}\text { Hb: NA / MCV: NA / SI:low } \\
\text { / TIBC:high / TS: NA / } \\
\text { fer:low / throm: NA } \\
\text { (numeric values NA) }\end{array}$ & $\begin{array}{l}\text { LMWH/ continued } \\
\text { resolution of } \\
\text { thrombosis at 6th } \\
\text { mo. }\end{array}$ & $\begin{array}{l}\text { PT, INR, PTT, Pr C, Pr S, } \\
\text { ATIII, homocysteine: N, } \\
\text { ACA, LA: (-) } \\
\text { MTHFR mutation (type } \\
\text { NA), Factor V Leiden: (-) }\end{array}$ & $\begin{array}{c}\text { Meckel } \\
\text { diverticulum }\end{array}$ \\
\hline \multirow[t]{2}{*}{$\begin{array}{l}\text { Bukarovich } \\
\text { IF et al. [32] }\end{array}$} & $\begin{array}{c}\text { Descending } \\
\text { thoracal } \\
\text { aorta (mobile } \\
\text { thrombus); } \\
\text { Right external iliac } \\
\text { artery, proximal } \\
\text { to midsuperficial } \\
\text { femoral arteries, } \\
\text { bilateral } \\
\text { profundafemoralis } \\
\text { arteries, right } \\
\text { hypogastric, } \\
\text { popliteal \& } \\
\text { anterior tibial } \\
\text { arteries }\end{array}$ & $42 \mathrm{y}, \mathrm{W}$ & $\begin{array}{l}\text { Hb:7.7 / MCV:65 / SI: NA / } \\
\text { TIBC: NA / TS: NA / fer: } 9 \text { / } \\
\text { throm: } 465000\end{array}$ & $\begin{array}{l}\text { Heparin, warfarin, } \\
\text { iron/ resolution at } \\
\text { 4th week }\end{array}$ & $\begin{array}{l}\text { ATIII, homocysteine, Pr } \\
\text { C:N; PAI-1: High; } \\
\text { ACA IgM/IgG, LA:(-); Pr } \\
\text { S: Mildly low } \\
\text { Prt G20210A, } \\
\text { Factor V Leiden: (-); EKG, } \\
\text { echocardiogram, upper } \\
\text { \& lower GIS endoscopy, } \\
\text { gynecologic evaluation: N }\end{array}$ & Menorrhagia \\
\hline & $\begin{array}{c}\text { Aortic arch (Mobile } \\
\text { thrombus; cerebral } \\
\text { infarct }\end{array}$ & $49 \mathrm{y}, \mathrm{W}$ & $\begin{array}{c}\text { Hb:8.4/ MCV:68/ SI:20/ } \\
\text { TIBC:NA / TS:NA/fer:15/ } \\
\text { throm: } 567000\end{array}$ & $\begin{array}{l}\text { Heparin, warfarin, } \\
\text { iron/ neurological } \\
\text { status improved } \\
\text { within } 10 \text { days }\end{array}$ & $\begin{array}{l}\text { ATIII, homocysteine, Pr C, } \\
\text { Pr S, PAI-1: N } \\
\text { ACA IgM/IgG, LA: (-) } \\
\text { Prt G20210A: (-), } \\
\text { Factor V Leiden: (-), } \\
\text { Echocardiography: N } \\
\text { except thrombus in aortic } \\
\text { arch, no GIS bleeding; } \\
\text { gynecological evaluation: } \\
\text { N }\end{array}$ & Menorrhagia \\
\hline
\end{tabular}




\begin{tabular}{|c|c|c|c|c|c|c|}
\hline $\begin{array}{c}\text { Benedict S } \\
\text { et al } \\
\text { [33] }\end{array}$ & $\begin{array}{c}\text { Straight sinus and } \\
\text { internal serebral } \\
\text { veins }\end{array}$ & $27 \mathrm{mo}, \mathrm{W}$ & $\begin{array}{l}\text { Hb:7/ MCV:45 / SI: NA } \\
\text { / TIBC: } 408 \text { / TS:NA / } \\
\text { fer:<2/ throm:248000 }\end{array}$ & $\begin{array}{l}\text { Thrombectomy, } \\
\text { heparin, warfarin, } \\
\text { blood transfusion, } \\
\text { iron/mild residual } \\
\text { left hemiparesis }\end{array}$ & $\begin{array}{c}\text { Hb electrophoresis: } \\
\text { Hb E:\%20.9; Pro C, } \\
\text { Pro S, homocysteine, } \\
\text { fibrinojen, FVIII:N; FV } \\
\text { Leiden, anticardiolipin } \\
\text { antibodies, ATIII, ANA: } \\
\text { (-) }\end{array}$ & $\begin{array}{c}\text { Fever } \& \text { headache } \\
\text { of } 10 \text { days } \\
\text { previously }\end{array}$ \\
\hline & $\begin{array}{l}\text { Venous thrombosis } \\
\text { in lateral ventricles }\end{array}$ & $9 \mathrm{mo}, \mathrm{W}$ & $\begin{array}{c}\text { Hb:6.6/ MCV:56.6/ SI:2/ } \\
\text { TIBC:267/ TS:1/ fer<2 / } \\
\text { throm:586000 }\end{array}$ & $\begin{array}{c}\text { Heparin, blood } \\
\text { transfusion, iron/ } \\
\text { sequelae (seizure } \\
\text { disorder, spastic } \\
\text { quadriparesis, static } \\
\text { encephalopathy, } \\
\text { hydrocephalus, visual } \\
\text { impairment) }\end{array}$ & $\begin{array}{c}\text { Pro C, Pro S, } \\
\text { homocysteine, ATIII: N; } \\
\text { FV Leiden, Prt G20210A } \\
\text { mutation, anticardiolipin } \\
\text { antibodies, lupus } \\
\text { anticoagulant: (-) }\end{array}$ & $\begin{array}{l}\text { Common cold \& } \\
\text { gastroenteritis } \\
\text { previously }\end{array}$ \\
\hline & $\begin{array}{c}\text { Straight } \\
\text { sinus and internal } \\
\text { cerebral veins } \\
\text { (hemorrhage in the } \\
\text { posterior } \\
\text { limb of the left } \\
\text { internal capsule, \& } \\
\text { edema bilaterally } \\
\text { in the basal ganglia } \\
\text { and thalami) }\end{array}$ & $19 \mathrm{mo}, \mathrm{M}$ & $\begin{array}{c}\text { Hb:6.9, MCV:50 / SI:54 / } \\
\text { TIBC:NA / TS: NA / fer: NA } \\
\text { / throm: } 408000\end{array}$ & $\begin{array}{l}\text { Urokinase, heparin, } \\
\text { dexamethasone, } \\
\text { blood transfusion, } \\
\text { iron/normal except } \\
\text { slight tremor in } \\
\text { upper extremities }\end{array}$ & $\begin{array}{l}\text { Hb electrophoresis, } \\
\text { Pro C,Pro S, ATIII, } \\
\text { homocysteine, } \\
\text { plasminogen:N; } \\
\text { FV Leiden, Prt } \\
20210 \text { mutations; } \\
\text { anticardiolipin antibo } \\
\text { dies: }(-)\end{array}$ & $\begin{array}{c}\text { Mild cough \& } \\
\text { vomiting for } 2 \text { days, } \\
\text { before presentation }\end{array}$ \\
\hline \multirow[t]{3}{*}{$\begin{array}{l}\text { Munot P et } \\
\text { al. [34] }\end{array}$} & $\begin{array}{c}\text { Right middle } \\
\text { cerebral artery } \\
\text { (territory infarct) }\end{array}$ & $14 \mathrm{mo}, \mathrm{W}$ & $\begin{array}{c}\text { Hb:2.5 / MCV: 64/ SI: NA/ } \\
\text { TIBC: NA / TS: NA / fer:13 } \\
\text { / throm:376000 }\end{array}$ & $\begin{array}{l}\text { ASA, iron/ MRA } \\
\text { normalized, } \\
\text { but severe left } \\
\text { hemiparesis } \\
\text { persisted }\end{array}$ & $\begin{array}{c}\text { Pr C, Pr S, ATIII, } \\
\text { plasminogen, activated } \\
\text { protein C ratio, Hb } \\
\text { electrophoresis:N; Factor } \\
\text { V Leiden, MTHFR- } \\
\text { PT20210 mutations, ACA, } \\
\text { LA: (-) }\end{array}$ & No \\
\hline & $\begin{array}{l}\text { Superior sagittal } \\
\text { sinus, transverse } \\
\text { sinus, frontal } \\
\text { cortical veins } \\
\text { (Bilateral } \\
\text { frontoparietal } \\
\text { venous infarcts) }\end{array}$ & $35 \mathrm{mo}, \mathrm{M}$ & $\begin{array}{l}\text { Hb:5.6 / MCV:53 / SI: } \\
\text { NA/ TIBC: NA/fer: NA/ } \\
\text { throm:257000 }\end{array}$ & $\begin{array}{l}\text { Transfusion, LMWH, } \\
\text { warfarin, iron /No } \\
\text { sequelae after } 1 \text { year }\end{array}$ & $\begin{array}{c}\text { Pr C, Pr S, ATIII, } \\
\text { plasminogen, activated } \\
\text { protein C ratio, Hb } \\
\text { electrophoresis:N; Factor } \\
\text { V Leiden, MTHFR-Prt } \\
20210 \text { mutations, ACA, } \\
\text { LA: (-); infection screen } \\
\text { of CSF: (-) }\end{array}$ & $\begin{array}{l}\text { Upper respiratory } \\
\text { tract infection, } \\
\text { sphenoid sinus } \\
\text { opacification }\end{array}$ \\
\hline & $\begin{array}{l}\text { Internal cerebral } \\
\text { veins, straight } \\
\text { sinus and vein } \\
\text { of Galen (diffuse } \\
\text { cerebral swelling, } \\
\text { hydrocephalus) }\end{array}$ & $2 \mathrm{y}, \mathrm{M}$ & $\begin{array}{l}\text { Hb:4.7 / MCV:54 / SI:8 / } \\
\text { TIBC:- / TS: NA / fer:35 / } \\
\text { throm:1744000 }\end{array}$ & $\begin{array}{c}\text { Heparin, warfarin, } \\
\text { iron/ mild dystonic } \\
\text { left hemiparesis after } \\
\text { 1 year }\end{array}$ & $\begin{array}{c}\text { Pr C, Pr S, ATIII, } \\
\text { plasminogen, activated } \\
\text { protein C ratio:N; Factor } \\
\text { V Leiden, MTHFR- } \\
\text { PT20210 mutations, } \\
\text { ACA, LA: (-); Hb } \\
\text { electrophoresis:Sickle } \\
\text { cell trait }\end{array}$ & No \\
\hline
\end{tabular}




\begin{tabular}{|c|c|c|c|c|c|c|}
\hline & $\begin{array}{l}\text { Posterior segment } \\
\text { of superior sagittal } \\
\text { sinus, torcula, } \\
\text { left transverse } \\
\text { sinus and internal } \\
\text { jugular vein }\end{array}$ & $40 \mathrm{mo}, \mathrm{M}$ & $\begin{array}{c}\text { Hb:7.7 / MCV:54 / SI: NA / } \\
\text { TIBC: NA / TS: NA / fer:5 / } \\
\text { throm: } 250000\end{array}$ & $\begin{array}{l}\text { LMWH, warfarin, } \\
\text { iron/Full recovery }\end{array}$ & $\begin{array}{c}\text { Pr C, Pr S, ATIII, } \\
\text { plasminogen, activated } \\
\text { protein C ratio, Hb } \\
\text { electrophoresis:N; Factor } \\
\text { V Leiden, MTHFR, Prt } \\
\text { G20210A mutations, } \\
\text { ACA, LA: (-); infection } \\
\text { screen of CSF: (-) }\end{array}$ & Left otitis media \\
\hline $\begin{array}{l}\text { Caglayan B } \\
\text { et al [35] }\end{array}$ & $\begin{array}{l}\text { Left internal } \\
\text { carotid artery } \\
\text { bifurcation }\end{array}$ & $41 y, W$ & $\begin{array}{c}\text { Hb:7.5 / MCV:58 / SI:12 / } \\
\text { TIBC:427 / TS: } 2.8 \text { / fer:12 } \\
\text { / throm: } 450000\end{array}$ & $\begin{array}{c}\text { Iron, heparin, } \\
\text { warfarin/ resolution } \\
\text { of thrombus }\end{array}$ & $\begin{array}{c}\text { Pr C, Pr S, ATIII, } \\
\text { fibrinojen, homocysteine, } \\
\text { VB12, folate, PT, } \\
\text { aPTT, LDL, HDL, } \\
\text { echocardiogram:N; } \\
\text { antiphospholipid } \\
\text { antibodies, ANA, anti } \\
\text { DNA, ANCA: (-) }\end{array}$ & Menorrhagia \\
\hline $\begin{array}{l}\text { Nakamizo T } \\
\text { et al [36] }\end{array}$ & $\begin{array}{l}\text { Thrombi in left } \\
\text { ventricle and right } \\
\text { int carotid artery, } \\
\text { occlusion in right } \\
\text { MCA }\end{array}$ & $45 y, W$ & $\begin{array}{c}\text { Hb:6/ MCV:65,3 / SI:19 / } \\
\text { TIBC:497 / TS:3.8/ fer:1.6 } \\
\text { / throm:573000 }\end{array}$ & $\begin{array}{l}\text { ASA, clopigodrel, } \\
\text { argatroban, iron/ } \\
\text { resolution of } \\
\text { thrombus }\end{array}$ & $\begin{array}{l}\text { Pr C, Pr S, ATIII: N; } \\
\text { antiphospholipid } \\
\text { antibodies: (-) }\end{array}$ & Menorrhagia \\
\hline $\begin{array}{l}\text { Steble G et } \\
\text { al [37] }\end{array}$ & $\begin{array}{l}\text { Superior sagittal } \\
\text { sinus }\end{array}$ & $46 y, M$ & $\begin{array}{l}\text { NA } \\
\text { (it is only said that he had } \\
\text { 'iron deficiency anemia') }\end{array}$ & Heparin/recovery & NA & Rectum prolapse \\
\hline $\begin{array}{c}\text { Ready WK } \\
\text { \& Lowry NJ } \\
{[38]}\end{array}$ & $\begin{array}{l}\text { İnfarction in the } \\
\text { left thalamus } \\
\text { and right } \\
\text { hypothalamus } \\
\text { (angiography NA) }\end{array}$ & $27 \mathrm{mo}, \mathrm{W}$ & $\begin{array}{l}\text { Hb:4.5/ MCV:50.2/ SI:NA/ } \\
\text { TIBC:NA / TS: NA/ fer: NA/ } \\
\text { throm:728000; peripheral } \\
\text { blood smear: signs of IDA }\end{array}$ & $\begin{array}{l}\text { NA/ slow, incomplete } \\
\text { recovery (cerebral } \\
\text { palsy) }\end{array}$ & $\begin{array}{c}\text { Serum chemistry: Mild } \\
\text { hypoproteinemia, } \\
\text { hypoalbuminemia, PT, } \\
\text { aPTT, Hb electrophoresis } \\
\text { N; Serum lead, ammonia: } \\
\text { N; CarboxyHb: (-) }\end{array}$ & $\begin{array}{c}\text { Diarrhea, vomiting, } \\
\text { fever }\end{array}$ \\
\hline $\begin{array}{l}\text { Meena AK } \\
\text { et al [39] }\end{array}$ & $\begin{array}{l}\text { Superior sagittal } \\
\text { sinus }\end{array}$ & $4 y, M$ & $\begin{array}{l}\text { Hb:8.3 MCV: NA / SI: NA / } \\
\text { TIBC: NA / TS: NA / fer:1.6 } \\
\text { / throm:1194000 }\end{array}$ & $\begin{array}{l}\text { Heparin, acitrom, } \\
\text { iron/steady } \\
\text { improvement }\end{array}$ & $\begin{array}{c}\text { Anti cardiolipin } \\
\text { antibodies (-), collagen } \\
\text { vascular disease profile, } \\
\text { Pro C, Pro S, ATIII, PT, } \\
\text { aPTT, FDP, fibrinogen, } \\
\text { total cho, LDL:N, } \\
\text { HDL:High }\end{array}$ & $\begin{array}{c}\text { Nephrotic } \\
\text { syndrome, } \\
\text { papilloedema }\end{array}$ \\
\hline \multirow[t]{2}{*}{$\begin{array}{c}\text { Aoki N \& } \\
\text { Sakai T [40] }\end{array}$} & $\begin{array}{c}\text { Superior sagittal } \\
\text { sinus (hemorrhagic } \\
\text { infarct) }\end{array}$ & $48 y, W$ & $\begin{array}{c}\text { Hb:6.8 MCV:NA / SI:54 / } \\
\text { TIBC:NA / TS: NA / fer: NA } \\
\text { / throm:125000 }\end{array}$ & & $\begin{array}{l}\text { PT, aPTT, FDP, } \\
\text { fibrinogen: } N\end{array}$ & $\begin{array}{l}\text { Mild papilloedema } \\
\text { Myoma uteri }\end{array}$ \\
\hline & $\begin{array}{l}\text { Left transverse } \\
\text { sinus (hemorrhagic } \\
\text { infarct) }\end{array}$ & $45 y, W$ & $\begin{array}{l}\text { Hb:5.9 MCV: NA / SI:NA / } \\
\text { TIBC: NA / TS:NA / fer: NA } \\
\text { / throm:171000 }\end{array}$ & & $\begin{array}{l}\text { Coagulation studies } \\
\text { \& blood chemistry: } \mathrm{N} \\
\text { (details NA) }\end{array}$ & .Myoma uteri \\
\hline
\end{tabular}

Abbreviations (Alphabetic order): ACA: Anti cardiolipin antibody, Abbreviations (Alphabetic order): ACA: Anti cardiolipin antibody, AMA: Anti-mitochondrial antibody, ANA: Antinuclear antibody, ANCA: Anti neutrophil cytoplasmic, antibody, Anti ds DNA: Anti deoxyribonucleic acid, ASA: acetylsalicylic acid, APA: Antiphospholipid antibody, ANCA: Antineutrophil cytoplasmic antibody, aPTT: Activated partial thromboplastin time, ATIII: Anti-thrombin III, CA-125: Cancer antigen 125, CRP: C-reactive protein, CSF: Cerebrospinal fluid, CT: Computerized tomography, ECG:Electrocardiogram, F: Factor , FDP: Fibrin degradation products, fer: Ferritin, G6PD: Glucose-6-Phosphate Dehydrogenase; HDL: High-density lipoprotein, Hb: Hemoglobin (g/dl), IDA: Iron deficiency anemia, INR: International normalized ratio, JAK-2: Janus kinase 2, LA: Lupus anticoagulant ; LDL: Low-density lipoprotein, LMWH: low molecular weight heparin, M: Male, MCV: Mean corpuscular volume, MHTFR: Methylene tetrahydrofolate reductase enzyme; MPL: Thrombopoietin receptor, MRA: Magnetic resonance angiography, MRI: magnetic resonans imaging, N: Normal, NA: Not available, PAI-1: Plasminogen activator inhibitor-1, PFO: Patent foramen ovale, PNH: Paroxysmal nocturnal 
hemoglobinuria, Pr C: Protein C, Pr S: Protein Santigen, PT: Prothrombin time, Prt: Prothrombin; RF: Rheumatoid factor, RistCoF: Ristocetin co factor, Sedim: Erythrocyte sedimentation rate, SI: Serum iron ( $\mu \mathrm{g} / \mathrm{dl})$, tPA: Tissue plasminogen activator, TAT: Thrombin Antithrombin Complex, throm: thrombocytes, TIBC: Total iron binding capacity ( $\mu \mathrm{g} / \mathrm{dl})$, TEE:Transesophageal echocardiogram, TS: Transferrin saturation(\%) TSH: Thyroid stimulating hormone, TT: Thrombin time, UIBC: Unsaturated iron binding capacity, USG: Ultrasonography, VB12: Vitamin B12, vWF A: von Willebrand factor antigen, W: women.

Table 3: Characteristics of 54 patients in the literature developing thrombosis on the basis of iron deficiency anemia (Summary).

\begin{tabular}{|c|c|c|c|c|c|c|c|c|c|c|c|c|c|}
\hline \multirow[b]{2}{*}{$\begin{array}{l}\text { Age } \\
\text { group }\end{array}$} & \multirow[b]{2}{*}{$\begin{array}{l}\text { Age } \\
\text { (medi } \\
\text { an) }\end{array}$} & \multirow{2}{*}{$\begin{array}{c}\text { Gender } \\
\text { (F/M/ } \\
\text { T) }{ }^{\circ}\end{array}$} & \multicolumn{3}{|c|}{$\begin{array}{l}\text { Total thrombosis attacks } \\
(\mathrm{n}, \%)\end{array}$} & \multicolumn{3}{|c|}{ Venous (n,\%) } & \multicolumn{3}{|c|}{ Arterial $(n, \%)$} & \multicolumn{2}{|c|}{$\begin{array}{l}\text { Total thrombosis } \\
\text { attacks }(n, \%)\end{array}$} \\
\hline & & & $\begin{array}{c}\text { Venous } \\
(n, \%)\end{array}$ & $\begin{array}{c}\text { Arterial } \\
(n, \%)\end{array}$ & $\begin{array}{l}\text { Total } \\
(n, \%)\end{array}$ & $\begin{array}{c}\text { Cereb } \\
\text { ral (n, } \\
\%)\end{array}$ & $\begin{array}{c}\text { Non } \\
\text { cereb } \\
\text { ral (n, } \\
\%)\end{array}$ & $\begin{array}{l}\text { Total } \\
(n, \%)\end{array}$ & $\begin{array}{l}\text { Cerebral } \\
(\mathrm{n}, \%)\end{array}$ & $\begin{array}{c}\text { Non } \\
\text { cereb } \\
\text { ral (n, } \\
\%)\end{array}$ & $\begin{array}{l}\text { Total } \\
\text { (n, } \\
\% \text { ) }\end{array}$ & $\begin{array}{c}\text { Cerebral } \\
\text { thrombosis } \\
\text { (venous+ } \\
\text { arterial) }\end{array}$ & Total \\
\hline Children & $23 \mathrm{mo}$ & $\begin{array}{c}14 \mathrm{~F} / 12 \mathrm{M} \\
/ 26\end{array}$ & $\begin{array}{c}19 \\
(73.1 \\
\%) \\
\end{array}$ & $\begin{array}{c}7 \\
-26.90 \%\end{array}$ & $\begin{array}{c}26 \\
(100 \%)\end{array}$ & $\begin{array}{c}19 \\
(100 \\
\%) \\
\end{array}$ & $0(0 \%)$ & $\begin{array}{c}19 \\
(100 \%)\end{array}$ & $\begin{array}{c}6 x \\
(85.7 \%)\end{array}$ & $\begin{array}{c}1^{*} \\
(14,3 \\
\%) \\
\end{array}$ & $\begin{array}{l}7(100 \\
\%)\end{array}$ & $\begin{array}{c}25 \\
-96.20 \%\end{array}$ & $\begin{array}{c}26 \\
(100 \\
\%)\end{array}$ \\
\hline Adults & $\begin{array}{l}504 \mathrm{mo} \\
(42 \mathrm{y})\end{array}$ & $\begin{array}{c}22 \mathrm{~F} / 6 \mathrm{M} \\
/ 28\end{array}$ & $\begin{array}{c}15 \\
(53.6 \\
\%)\end{array}$ & $\begin{array}{c}13 \\
-46.40 \%\end{array}$ & $\begin{array}{c}28 \\
(100 \%)\end{array}$ & $\begin{array}{c}10 \\
(66.6 \\
\%)\end{array}$ & $\begin{array}{c}5^{* *} \\
(33.3 \%)\end{array}$ & $\begin{array}{c}15 \\
-100 \%\end{array}$ & $\begin{array}{c}3 \\
(23.1 \%)\end{array}$ & $\begin{array}{c}10^{* * *} \\
(76.9 \\
\%)\end{array}$ & $\begin{array}{c}13 \\
-100 \\
\% \\
\end{array}$ & $\begin{array}{c}13 \\
-46.40 \%\end{array}$ & $\begin{array}{c}28 \\
-100 \%\end{array}$ \\
\hline All & $\begin{array}{c}228 \mathrm{mo} \\
(19 \mathrm{y})\end{array}$ & $\begin{array}{c}36 \mathrm{~F} / 18 \mathrm{M} \\
/ 54\end{array}$ & $\begin{array}{c}34 \\
-62.90 \\
\%\end{array}$ & $\begin{array}{c}20 \\
(37 \%)\end{array}$ & $\begin{array}{c}54 \\
(100 \%)\end{array}$ & $\begin{array}{c}29 \\
(85.3 \\
\%)\end{array}$ & $\begin{array}{c}5 \\
(14.7 \%)\end{array}$ & $\begin{array}{c}34 \\
-100 \%\end{array}$ & $9(45 \%)$ & $\begin{array}{c}11(55 \\
\%)\end{array}$ & $\begin{array}{c}20 \\
-100 \\
\%\end{array}$ & $\begin{array}{c}38 \\
-70.30 \%\end{array}$ & $\begin{array}{c}54 \\
-100 \%\end{array}$ \\
\hline
\end{tabular}

${ }^{\circ}$ : Female/Male/Total; ${ }^{\star} 1 / 6$ had a coexistent thrombus in the atrium, *Thrombosis of retinal artery, ${ }^{* *}$ All are thrombosis of retinal vein, ${ }^{* * *} 6 / 10$ are thrombosis of carotid artery, one of them being coexistent with another thrombosis in the ventricle, $3 / 10$ are thrombosis of aorta, 1/10 is thrombosis of retinal artery

Forty one out of 54 cases (75.9\%) had at least one associated condition like infections (n:13), menorrhagia (n:10), gastrointestinal disorder like diverticulosis, rectal prolapsus, hemorrhoids (n:3), gastrointestinal hemorrhage (n:3), myoma uteri (n:3), dehydratation ( $n: 2)$, oncologic problems like adenomyosis, endometriosis and myeloid metaplasia (n:2), papilledema (n:2), anorexia nervosa (n:1), nephrotic syndrome (n:1), migraine (1), retinal hemorrhage (n:1), bronchial asthma (n:1), alcoholism (n:1) (Table 2). All the 13 cases with concomitant infection were children all of whom had cerebral vessel occlusions, the majority involving the cerebral veins (n:9). The six had gastroenteritis, the three had otitis media, and the rest had various infections [3-15, 17-40] (Table 2).

\section{Discussion}

In this study, we presented two patients with cerebral thrombosis and IDA that were followed in our clinic and reviewed the literature. Of the 54 thrombosis cases with ID/IDA in the literature, cerebral thrombosis made up of $70.4 \%$ of all the cases, venous cerebral occlusions comprising $100 \%$ and $66 \%$ of venous thrombosis in children and adults respectively. Our report highlights the importance of prevention and early treatment of ID/ IDA, especially in children. That, the frequency of ID/IDA in our patients with thrombosis $(11.8 \%$, Table 2$)$ was lower than that in the literature (15-29\%) [42] may be related to limited number of cases in our cohort. Our first case emphasizes the importance of preceeding/concomitant otitis media or mastoiditis as prothrombotic risk factors which were reported to accompany 24$62 \%$ of cerebral sinovenous thrombosis cases in children, among various infections [43]. The role of reactive thrombocytosis in the pathogenesis of thrombosis in ID/IDA is controversial [5,7,8,44,45]. However, the reduced cell deformability caused by microcytosis in ID/IDA causes hypercoagulation $[3,7,45]$ through increasing blood viscosity and disrupting the normal blood flow pattern [3]. Concomitant dehydration, metabolic stress and infections increase metabolic demand of tissues, especially those of the basal ganglia, thalamus, hypothalamus $[3,45]$, leading to anemic hypoxia and therefore venous thrombosis [7]. Endothelial damage develops [4648] due to increase in oxidants [49] and reduction of antioxidants $[49-53,54]$ in ID/IDA, although controversial results are also available [55] and because of turbulant flow, which is a result of vasodilation and increased blood viscosity [17], thereby stimulating thrombocyte aggregation and thrombosis. However the effect of IDA on thrombocyte aggregation is controversial [46,56,57]. On the other hand, increased plasminogen activator inhibitor [58] was also reported. Whether clotting time is shortened and coagulation factors are increased like in other disorders like hemodilution [58], hemorrhagic shock [59] require further studies.

The idea that ID/IDA is a predisposing factor for thrombosis is relatively new. Our recent study with thromboelastography showed that IDA patients had a tendency to hypercoagulation [41]. That none of these patients had developed thrombosis suggested that additional thrombophilia factors may be required for development of thrombosis. The accompaniment of additional prothrombotic risk factors in our patients and those in the literature, although in various rates, support this hypothesis. Indeed, Stolz et al. showed that severe anemia is an independent risk factor for cerebral venous 
thrombosis only when it is together with hypercholesterolemia and thrombophilia [1]. The main limitation of our study is that iron parameters were considered as prerequisite prothrombotic factors to be evaluated only after 2014 in our clinic; so only 17 cases could be evaluated. Incomplete search of additional prothrombotic risk factors of the cases in the literature are the limitations of the literature review.

\section{Conclusion}

Iron deficiency anemia or ID is a prothrombotic factor, as reported previously $[60,61]$. Two of our cases and 54 cases in the literature revealed coexistence of ID/IDA and thrombosis. Involvement of cerebral vessels in the majority of cases in childhood is striking. Further investigations are required to evaluate the role of additional prothrombotic risk factors in thrombosis that develops in ID/IDA patients.

\section{References}

1. Stolz E, Valdueza JM, Grebe M, Schlachetzki F, Schmitt E (2007) Anemia as a risk factor for cerebral venous thrombosis? An old hypothesis revisited. Results of a prospective study. Journal of Neurology 254(6): 729-734.

2. Hung S, Lin H, Chung S (2015) Association between venous thromboembolism and iron- deficiency anemia: a population-based study. Blood Coagulation \& Fibrinolysis 26(4): 368-372.

3. Hartfield DS, Lowry NJ, Keene DL, Yager JY (1997) Iron deficiency: a cause of stroke in infants and children. Pediatric Neurology 16(1): 5053.

4. Belman AL, Roque CT, Ancona R, Anand A, Davis R (1990) Cerebral venous thrombosis in a child with iron deficiency anemia and thrombocytosis. Stroke 21(3): 488-493.

5. Balci K, Utku U, Asil T, Büyükkoyuncu N (2007) Deep cerebral vein thrombosis associated with iron deficiency anaemia in adults. Journal of Clinical Neuroscience 14(2): 181-184.

6. Kinoshita Y, Taniura S, Shishido H, Nojima T, Kamitani H, et al. (2006) Cerebral venous sinus thrombosis associated with iron deficiency: two case reports. Neurologia Medico-Chirurgica 46(12): 589-593.

7. Sushil B, Khan A, Hussain N, Gosalakkal J (2012) Severe anemia causing cerebral venous sinus thrombosis in an infant. Journal of Pediatric Neurosciences 7(1): 30-32.

8. Yokota H, Ida Y, Sugiura S, Sasaki K, Itoh H (2014) Cerebral venous sinus thrombosis with increased factor VIII activity in an adult with iron deficiency anemia. Neurology India 62(6): 674-675.

9. Corrales Medina F, Grant L, Egas Bejar D, Valdivia Ascuna Z, Rodriguez $\mathrm{N}$, et al. (2014) Cerebral sinovenous thrombosis associated with iron deficiency anemia secondary to severe menorrhagia: A case report. Journal of Child Neurology 29(9): NP62-NP64.

10. Lee JH, Park KJ, Chung YG, Kang SH (2013) Isolated lateral sinus thrombosis presenting as cerebellar infarction in a patient with iron deficiency anemia. Journal of Korean Neurosurgical Society 54(1): 4749.

11. Ghosh PS, Plautz G, Cerejo R, Moodley M (2014) Cerebral venous sinus thrombosis in a child with iron-deficiency anemia. Acta Neurologica Belgica 114(2): 131-132.

12. Karakurum G, Karaca S, Alkan O, Yildirim T (2012) Isolated inferior sagittal sinus thrombosis caused by a rare combination of elevated lipoprotein (a) and iron deficiency anemia. Neurosciences (Riyadh) 17(4): 374-377.
13. Basak R, Chowdhury A, Fatmi L, Saha N, Mollah A, et al. (2008) Stroke in the young: relationship with iron deficiency anemia and thrombocytosis. Mymensingh Medical Journal 17(1): 74-77.

14. Saxena K, Ranalli M, Khan N, Blanchong C, Kahwash SB (2005) Fatal stroke in a child with severe iron deficiency anemia and multiple hereditary risk factors for thrombosis. Clinical Pediatrics 44(2): 175180.

15. Ogata T, Kamouchi M, Kitazono T, Kuroda J, Ooboshi H, et al. (2008) Cerebral venous thrombosis associated with iron deficiency anemia. Journal of Stroke and Cerebrovascular Diseases 17(6): 426-428.

16. Chang LY, Hung SH, Ling W, Lin HC, Li HC, et al. (2013) Association between ischemic stroke and ron-deficiency anemia: a populationbased study. PLoS One 8(12): e82952.

17. Akins PT, Glenn S, Nemeth PM, Derdeyn CP (1996) Carotid artery thrombus associated with severe iron-deficiency anemia and thrombocytosis. Stroke 27(5): 1002-1005.

18. Imai E, Kunikata H, Udono T, Nakagawa Y, Abe T, et al. (2004) Branch retinal artery occlusion: a complication of iron-deficiency anemia in a young adult with a rectal carcinoid. The Tohoku Journal of Experimental Medicine 203(2): 141-144.

19. Kirkham TH, Wrigley PF, Holt JM (1971) Central retinal vein occlusion complicating iron deficiency anaemia. The British Journal of Ophthalmology 55(11): 777-780.

20. Kacer B, Hattenbach LO, Hörle S, Scharrer I, Kroll P, et al. (2001) Central retinal vein occlusion and nonarteritic ischemic optic neuropathy in 2 patients with mild iron deficiency anemia. Ophthalmologica 215(2): 128-131.

21. Nagai T, Komatsu N, Sakata Y, Miura Y, Ozawa K (2005) Iron deficiency anemia with marked thrombocytosis complicated by central retinal vein occlusion. Internal Medicine 44(10): 1090-1092.

22. Matsuoka Y, Hayasaka S, Yamada K (1996) Incomplete occlusion of central retinal artery in a girl with Iron deficiency anemia. Ophthalmologica 210(6): 358-360.

23. Shibuya Y, Hayasaka S (1995) Central retinal vein occlusion in a patient with anorexia nervosa. American Journal of Ophthalmology 119(1): 109-110.

24. Knizley H Jr, Noyes WD (1972) Iron deficiency anemia, papilledema, thrombocytosis, and transient hemiparesis. Archives of Internal Medicine 129(3): 483-486.

25. Alexander MB (1983) Iron deficiency anemia, thrombocytosis, and cerebrovascular accident. Southern Medical Journal 76(5): 662-663.

26. Heller DS, Pervez NK, Kleinerman J (1988) Fatal cerebrovascular thrombosis in a young woman: an unusual complication associated with hypochromic anemia and thrombocytosis following surgery. Mt Sinai J Med 55(4): 318-320.

27. Boon IS, Starkey KJ, Samsonova O, Johnston AM (2016) In the thick of it: cerebral venous sinus thrombosis precipitated by iron-deficiency anaemia and sickle cell trait. BMJ Case Reports.

28. Nishioka K, Tanaka R, Tsutsumi S, Yamashiro K, Nakahara M, et al. (2014) Cerebral dural sinus thrombosis associated with adenomyosis: a case report. Journal of Stroke and Cerebrovascular Diseases 23(7): 19851987.

29. Raso S, Napolitano M, Saccullo G, Siragusa S (2016) Abdominal aortic thrombosis secondary to reactive thrombocytosis in a patient with iron deficiency anemia. Annals of Hematology 95(8): 1389-1390.

30. Nicastro N, Schnider A, Leemann B (2012) Iron-deficiency anemia as a rare cause of cerebral venous thrombosis and pulmonary embolism. Case Reports in Medicine, pp. 497814.

31. Habis A, Hobson WL, Greenberg R (2010) Cerebral sinovenous thrombosis in a toddler with iron deficiency anemia. Pediatric Emergency Care 26(11): 848-851. 
32. Bukharovich IF, Wever Pinzon 0, Ajay Shah A, Todd G, Chaudhry FA, et al. (2012) Arterial embolism caused by large mobile aortic thrombus in the absence of atherosclerosis, associated with iron deficiency anemia. Echocardiography 29(3): 369-372.

33. Benedict SL, Bonkowsky JL, Thompson JA, Colin B, Van Orman CB, et al. (2004) Cerebral Sinovenous Thrombosis in Children: Another Reason to Treat Iron Deficiency Anemia. Journal of Child Neurology 19(7): 526531.

34. Munot P, De Vile C, Hemingway C, Gunny R, Ganesan V (2011) Severe iron deficiency anaemia and ischaemic stroke in children. Archives of Disease in Childhood 96(3): 276-279.

35. Caglayan B, Nazliel B, Irkec C, Dumlu A, Filiz A, et al. (2013) Iron deficiency anemia leading to transient ischemic attacks due to intraluminal carotid artery thrombus. Case Reports in Neurological Medicine 2013: 813415.

36. Nakamizo T, Ishikawa K, Amari K (2014) Simultaneous thrombosis in a normal left ventricle and normal carotid artery in a patient with a stroke secondary to iron deficiency anemia. Journal of Medical Cases 5(6): 351 354.

37. Stehle G, Boss J, Heene DL (1991) Noninfectious thrombosis of the superior sagittal sinus in a patient with iron deficiency anemia. Stroke 22(3): 414

38. Ready WK, Lowry NJ (1989) Anemia causing cerebral infarction in a child. Canadian Medical Association Journal 140(3): 303-304.

39. Meena AK, Naidu KS, Murthy JM (2000) Cortical sinovenous thrombosis in a child with nephrotic syndrome and iron deficiency anaemia. Neurology India 48(3): 292-294

40. Aoki N, Sakai T (1989) Cerebral sinus thrombosis in patients with severe iron deficiency anaemia due to myoma uteri. Acta Neurochirurgica 97(34): 131-134.

41. Kılcı C (2016) Demir eksikliğinde görülen trombozun patogenezine yaklaşım: Koagulasyonun tromboelastografi ile değerlendirilmesi, Uzmanlık tezi, Ankara, Turkey.

42. Kaiafa G, Savopoulos C, Kanellos I, Mylonas KS, Tsikalakis G, et al. (2017) Anemia and stroke: Where do we stand?. Acta Neurologica Scandinavica 135(6): 596-602.

43. Dlamini N, Billinghurst L, Kirkham FJ (2010) Cerebral venous sinus (sinovenous) thrombosis in children. Neurosurgery Clinics of North America 21(3): 511-527.

44. Toprak S, Tek İ, Karakuș S, Gök N, Nazmiye Kurșun N (2012) Does reactive thrombocytosis observed in iron deficiency anemia affect plasma viscosity? Turkish Journal of Hematology 29(3): 248-253.

45. Franchini M, Targher G, Montagnana M, Lippi G (2008) Iron and thrombosis. Annals of Hematology 87(3): 167-173.

46. Tekin D, Yavuzer S, Tekin M, Akar N, Cin S (2001) Possible effects of antioxidant status on increased platelet aggregation in childhood irondeficiency anemia. Pediatrics International 43(1): 74-77.

47. Jansson LT, Perkkio MV, Willis WT, Refino CJ, Dalman PR (1985) Red cell superoxide dismutase is increased in iron deficiency anemia. Acta Haematologica 74(4): 218-221.
48. Acharya J, Punchard NA, Taylor JA, Thompson RP, Pearson TC (1991) Red cell lipid peroxidation and antioxidant enzymes in iron deficiency. European Journal of Haematology 47(4): 287-291

49. Kurtoglu E, Ugur A, Baltaci AK, Undar L (2003) Effect of iron supplementation on oxidative stress and antioxidant status in irondeficiency anemia. Biological Trace Element Research 96(1-3): 117-123.

50. Isler M, Delibas N, Guclu M, Gultekin F, Sutcu R, et al. (2002) Superoxide dismutase and glutathione peroxidase in erythrocytes of patients with iron deficiency anemia: effects of different treatment modalities. Croatian Medical Journal 43(1): 16-19.

51. Perona G, Cellerino R, Guidi GC, Moschini G, Stievano BM, et al. (1977) Erythrocytic glutathione peroxidase: its relationship to plasma selenium in man. Scandinavian Journal of Haematology 19(1): 116-120.

52. Cellerino R, Guidi G, Perona G (1976) Plasma iron and erythrocytic glutathione peroxidase activity. A possible mechanism for oxidative haemolysis in iron deficiency anemia. Scandinavian Journal of Haematology 17(2): 111-116.

53. Yetgin S, Gonenc C, Cigdem A (1986) Neutrophil glutathione peroxidase activity in iron deficiency anaemia. Scandinavian Journal of Haematology 36(1): 58-60.

54. Kumerova A, Lece A, Skesters A, Silova A, Petuhovs V (1998) Anemia and antioxidant defence of the red blood cells. Materia Medica Polona 30(12): 12-15.

55. Meral A, Tuncel P, Surmen E, Ozbek R, Ozturk E, et al. (2000) Lipid peroxidation and antioxidant status in beta-thalassemia. Pediatric Hematology Oncology 17(8): 687-693.

56. Calışkan U, Oner AF, Kabakus N, Koc H (1999) Diminished platelet aggregation in patients with iron deficiency anemia. Clin Appl Thromb Hemost 5(3): 161-163.

57. Kawecki AE, Atay AA, Sarıcı SU, Zeybek C, Köseoğlu V, et al. (2000) Effect of iron therapy on the whole blood trombosit aggregation in infants with iron deficiency anemia. Thrombosis Research 97(5): 281-285.

58. Bennett PC, Silverman SH, Gill PS, Lip GY (2009) Peripheral arterial disease and Virchow's triad. Thrombosis and Haemosthasis 101(6): 1032-1040.

59. Turpini R, Stefanini M (1959) The nature and mechanism of the hemostatic breakdown in the course of experimental hemorrhagic shock. The Journal of Clinical Investigation 38 (1, Part 1): 53-65.

60. Potaczek DP, Jankowska EA, Wypasek E, Undas A (2016) Iron deficiency: a novel risk factor of recurrence in patients after unprovoked venous thromboembolism. Polskie Archiwum Medycyny Wewnetrznej 126(3): 159-165.

61. Raskob GE, Angchaisuksiri P, Blanco AN, Buller H, Gallus A, et al. (2014) Thrombosis: a major contributor to the global disease burden. Journal of Thrombosis and Haemostasis 12(10): 1580-1590. 


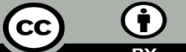

This work is licensed under Creative Commons Attribution 4.0 License

To Submit Your Article Click Here: Submit Article

DOI: $10.32474 /$ OAJOM.2018.02.000139

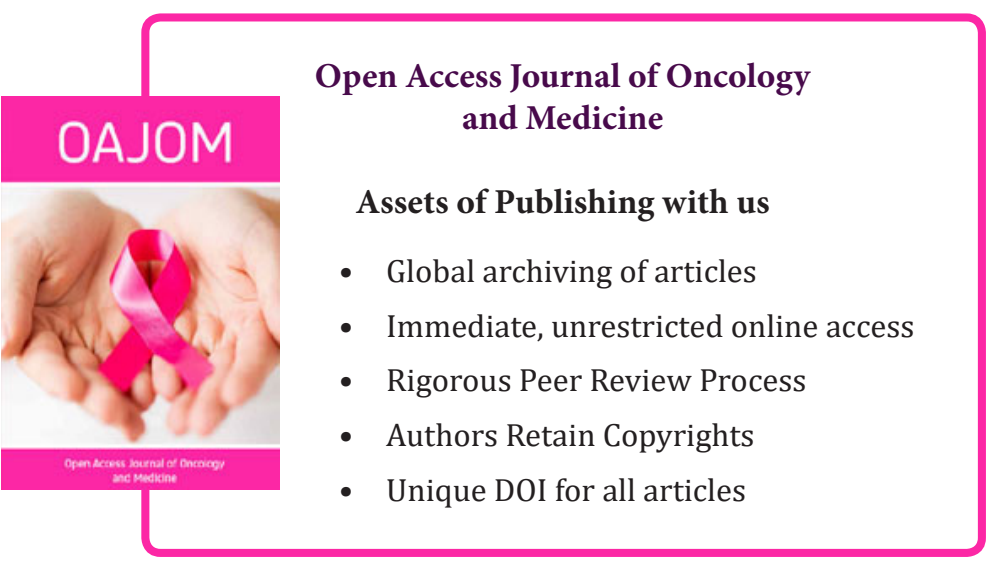

